\title{
Species-Dependent Variables in Blood Cerebrospinal Fluid Barrier Function for Proteins
}

\author{
By H. Reiber and P. Thiele
}

Neurochemisches Labor der Neurologischen Klinik der Universität, Göttingen, FRG

(Received August 25/December 1, 1982)

Summary: Cerebrospinal fluid/plasma concentration quotients for immunoglobulin $G$ (I) and albumin (A) were determined in guinea pigs. Age and sex-dependent influences on these quotients (I/A) were analysed and compared with the values for human lumbar, cisternal and ventricular cerebrospinal fluid. The rato I/A, which characterizes the molecular size-dependent selectivity of the blood cerebrospinal fluid barrier function for proteins, was found to be a constant in a single species, but showed marked interspecies differences.

\section{Spezies-abhängige Variable der Blut-Liquor-Schrankenfunktion für Proteine}

Zusammenfassung: Die Liquor/Plasma Konzentrationsquotienten von Immunglobulin $G$ (I) und Albumin (A) des Meerschweinchens wurden bestimmt. Alters- und Geschlechts-bedingte Einflüsse auf die Quotienten $(\mathrm{I}, \mathrm{A})$, als auch auf das Quotientenverhältnis I/A wurden untersucht und mit den Werten für den menschlichen lumbalen, cisternalen und Ventrikel-Liquor verglichen. Das Verhältnis I/A, das die Molekülgrößenabhängige Selektivität der Blut-Liquor-Schrankenfunktion charakterisiert, ist eine Konstante in der einzelnen Spezies, variiert aber stark von Spezies zu Spezies.

\section{Introduction}

The protein concentrations in human cerebrospinal fluid (CSF) are used for the diagnosis of neurological diseases, especially the identification of blood CSF barrier dysfunctions and local immune response in central nervous system (ref. cited in 1.c. (1)). A corresponding analysis of the protein concentrations in CSF of guinea pigs with chronic relapsing experimental allergic encephalomyelitis is of interest, because this experimentally induced disease is accepted as a model for multiple sclerosis in man (2). We therefore compared the normal CSF protein profile and normal blood CSF barrier functions in guinea pig and man. In addition, we compared the selectivity coefficients as an expression of the molecular sizedependent discrimination of the barrier function, which is represented by the ratio of the CSF/plasma concentration gradients of two proteins with different hydrodynamic radius (4). In the present work, this ratio, introduced earlier (ref. in l.c. $(1,4)$ ), was investigated with respect to its constancy throughout the whole CSF space, and with respect to sex, age and species-dependent variations.

\section{Methods}

Sampling of CSF

Anaesthetised strain 13 guinea pigs were punctured for cisternal CSF by an improved method (3). By this percutaneous suboccipital puncture about 30-330 $\mu \mathrm{l}$ CSF were extracted with a sufficiently low artefactual blood contamination to calculate a correction.

The red and the white blood cells were counted in a Fuchs-Rosenthal counting chamber. Cell counting was done whenever CSF was collected, because even a small contamination with blood can significantly increase the protein concentration, e.g. at a blood: CSF volume ratio of 0.0005 (erythrocyte count $\approx 2500 / \mu l$ CSF) the C.SF protein concentration is increased by more than $10 \%$.

Blood samples were removed by cardiac puncture, collected in heparinized tubes and centrifuged to obtain plasma for further analysis. 


\section{Protcin estimations}

$\operatorname{IgG}$ and albumin in CSF and plasma were determined by a nephelometric immunochemical method on a Beckman ICS-Nepheloneter: To $500 \mu \mathrm{l}$ of a polyethylene glycol solution $(4 \mathrm{~g} / \mathrm{l})$ in phosphate buffer $(0.1 \mathrm{~mol} / \mathrm{pH}=7.0) 20 \mu \mathrm{l}$ antibody solution and $10 \mu \mathrm{l}$ sample were added, containing about $0.15 \mu \mathrm{g}$ albumin or $\mathrm{lgG}$. After onc hour incubation at room temperature light scattering intensity was measured in the sample, in a series of calibration standards, in a control serum and in several blanks. Corresponding CSF and plasma samples were analysed in the same series. Standards guinea pig IgG and albumin were from Sigma. Rabbit anti guinea pig albumin antiserum (lyophilised) was from Paesel. Frankfurt and goat anti guinea pig IgG antiserum from Miles. Antibody solutions were prediluted in the polyethylene glycol containing phosphate buffer and centrifuged to eliminate precipitated unstable components.

\section{Correction for blood contamination in CSF}

IgG and albumin concentrations in CSF were corrected by the formula $c_{i}^{\prime}=c_{f}-(z / v) c_{p}$ where $c_{f}$ represents the albumin or IgG concentration determined in CSF, $c_{\mathrm{p}}$ represents the corresponding albumin or IgG concentration in plasma of the same animal, $z$ represents the red blood cell count $(\leqslant 7000 / \mu \mathrm{l})$ in CSF and $v$ represents the erythrocyte count mean value in blood $\left(5 \cdot 10^{6} / \mu \mathrm{l}\right.$ for adult animals).

\section{Results}

The immunochemical analysis of IgG and albumin in plasma and CSF of guinea pigs had a day-to-day precision $(\mathrm{n}=15)$ with the following coefficients of variation: $\mathrm{CV}=5 \%(14 \mathrm{mg} / \mathrm{l}$ albumin $)$ and $\mathrm{CV}=7 \%$ $(22 \mathrm{mg} / \mathrm{IgG})$. The corresponding precision in series $(\mathrm{n}=5)$ was $\mathrm{CV}=2.2 \%$ (albumin) and $\mathrm{CV}=1.3 \%$ (IgG). The CSF protein concentrations were corrected for a possible artefactual blood contamination using the red blood cell count (RBC). Normal cell counts in CSF of guinea pigs are $0 / \mu$ l and white blood cells $\leqslant 4 / \mu$ l.

The normal values of the protein concentrations in plasma of $\mathrm{n}=36$ adult guinea pigs were (mean $\pm \mathrm{CV}$ ): Total protein $55 \mathrm{~g} / 1 \pm 7.7 \%$, albumin $39.6 \mathrm{~g} / \pm 8.6 \%$ and $\mathrm{IgG} 6.8 \mathrm{~g} / \pm 27 \%$. Young animals ( 21 days old, $\mathrm{n}=15$ ) had lower serum protein concentrations with $30.5 \mathrm{~g} / 1 \pm 8.2 \%$ (albumin) and $2.2 \mathrm{~g} / \pm 16 \%$ ( $\mathrm{IgG}$ ). The corresponding CSF protein concentrations in adult animals (values of young animals in brackets) were $87 \mathrm{mg} / \pm \pm 16 \%$ $(85 \mathrm{mg} / \pm 17 \%)$ for albumin, and $12 \mathrm{mg} / \pm 25 \%$ $(5.3 \mathrm{mg} / \mathrm{l} \pm 28 \%)$ for $\mathrm{IgG}$.

For several reasons $(1,4)$ it is advantageous to evaluate the CSF protein data by the correlation of $\mathrm{CSF} /$ plasma concentration quotients. In figure 1 the IgG CSF/plasma concentration quotient I ( $\mathrm{I}=\mathrm{IgG}$ (CSF) $\cdot 10^{3} / \mathrm{lgG}$ (plasma)) is plotted as a function of the individual blood CSF barrier function characterized by the albumin CSF/plasma concentration quotient A $\left(\mathrm{A}=\right.$ albumin $(\mathrm{CSF}) \cdot 10^{3} / \mathrm{albumin}$ (plasma)).
The regression line $\left(I^{\prime}=0.66 \mathrm{~A}+0.32\right)$ with a standard deviation $\mathrm{s}_{\mathrm{yx}}^{\prime}=0.20$ and a correlation coefficient $r=0.80$ had an ordinate segment. For biochemical and theoretical reasons (6) the regression line ought to go through the origin and the mean values $(\overline{\mathrm{I}}, \overline{\mathrm{A}})$ of the group. The correspondingly corrected regression line was used in figure 1 with $\overline{\mathrm{I}}=0.8 \overline{\mathrm{A}}$. The recalculated standard deviation of $s_{y x}=0.22$ differed little from the empirical value $\left(s_{y x}^{\prime}\right)$. The reference range for the total group of adult animals (dashed lines in fig. 1) was constructed with the corrected regression line $\pm 2 \mathrm{~s}_{\mathrm{yx}}$ and the mean albumin quotient $\pm 2 \mathrm{SD}(2.17 \pm 0.83)$.

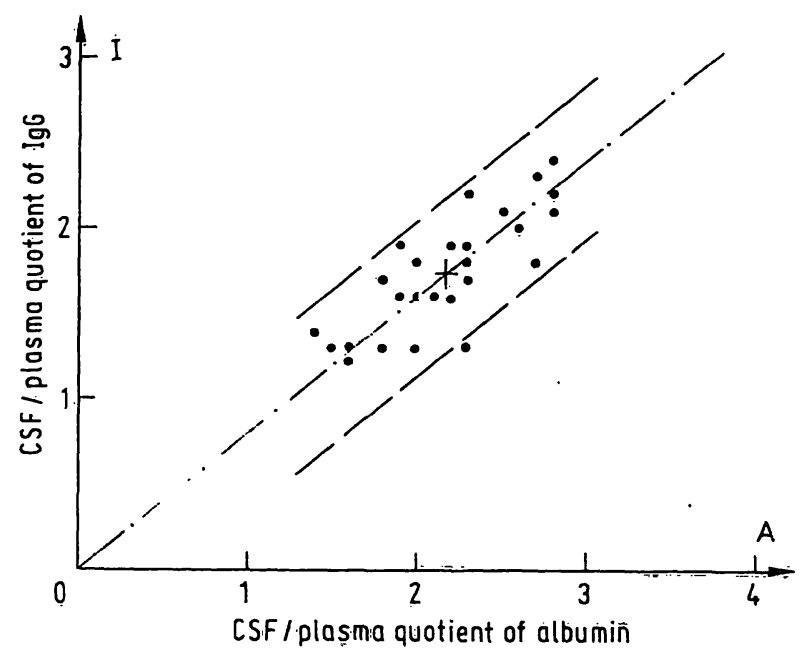

Fig. 1. Reference range for CSF/plasma concentration quotients of IgG and albumin from guinea pig strain 13. Cisternal CSF, $\mathrm{n}=26$ adult animals $(19 \delta, 7 \%) ; \mathrm{I}=\mathrm{IgG}$ (CSF) $\cdot 10^{3} / \mathrm{lgG}$ (plasma); $\mathrm{A}=$ albumin (CSF) $\cdot 10^{3} / \mathrm{al}$ bumin (plasma). The reference range (dashed line) is defined by the regression line,$I=0.8 \mathrm{~A} \pm 2 \mathrm{~s}_{\mathrm{yx}}$ with $\mathrm{S}_{\mathrm{yx}}=0.22$ and the mean albumin quotient with twofold standard deviation $(\overline{\mathrm{A}} \pm 2 \mathrm{SD}=2.17 \pm 0.83)$.

Thus this reference range includes $96 \%$ of the normal cases. Values of $\mathrm{A}>3.0$ indicate blood CSF barrier dysfunctions in adult guinea pigs. But this value varies with age and sex of the animals (tab. 1).

In spite of the variations of the albumin quotient there was no difference in the ratio $\overline{\mathrm{I}} / \overline{\mathrm{A}}$ in the different guinea pig groups (tab. 1). This ratio of the quotients $\overline{\mathrm{I}} / \overline{\mathrm{A}}$ is also represented by the slope of the regression line in figure 1 and characterizes the differences in barrier permeability for different proteins due to the different size of the protein molecules (4).

In man there is a large variation in the albumin $\mathrm{CSF} /$ plasma quotient as a consequence of the caudal to rostral concentration gradient in the CSF space (tab. 1). In spite of this large variation in the albumin quotient there is a constant ratio $\overline{\mathrm{I}} / \overline{\mathrm{A}}$ in the whole CSF space: $\overline{\mathrm{I}} / \overline{\mathrm{A}}=0.43$ or 0.39 or 0.38 for lumbar, cisternal or ventricular CSF respectively (tab. 1). 
Tab. 1. Variations in blood CSF barrier function for proteins in guinea pig and man.

$\bar{A}(C V)=$ mean and coefficient of variation (\%) of the albumin CSF/plasma concentration quotient $\left(\mathrm{A}=\mathrm{albumin}(\mathrm{CSF}) \cdot 10^{3} /\right.$ albumin (plasma)); $\bar{I}=$ mean of IgG CSF/plasma concentration quotient ( $\mathrm{I}=\mathrm{IgG}(\mathrm{CSF}) \cdot 10^{3} / \mathrm{IgG}$ (plasma)). Concentrations were inserted in the same units for CSF and plasma. $\overline{\mathrm{I}} / \overline{\mathrm{A}}=$ discrimination ratio for molecular size-dependent permeability (identical with the mean of the IgG index (8)).

The data were from cisternal CSF of $n=26(19 \delta, 7 \%)$ adult strain 13 guinea pigs and $n=9$ young animals (21 days old). The values for human ventricular and cisternal CSF were calculated from 1.c. (5) and the values for human lumbar CSF stem from I.c. (1). All human values refer to adults and are not differentiated for'sex.

\begin{tabular}{llllllll}
\hline & $\begin{array}{l}\text { Guinea pig } \\
\text { Adults } \\
\delta\end{array}$ & $\begin{array}{l}\text { Adults } \\
\Phi\end{array}$ & $\begin{array}{l}\text { Adults } \\
\text { total }\end{array}$ & $\begin{array}{l}\text { Young } \\
\text { total }\end{array}$ & $\begin{array}{l}\text { Man } \\
\text { Ventricular } \\
\text { CSF }\end{array}$ & $\begin{array}{l}\text { Cisternal } \\
\text { CSF }\end{array}$ & $\begin{array}{l}\text { Lumbar } \\
\text { CSF }\end{array}$ \\
\hline$\overline{\mathrm{A}}(\mathrm{CV} \%)$ & $2.0(17)$ & $2.6(9)$ & $2.2(19)$ & $2.9(17)$ & $2.0(30)$ & $3.1(32)$ & $4.6(30)$ \\
$\overline{\mathrm{I} / \overline{\mathrm{A}}}$ & 0.80 & 0.80 & 0.80 & 0.76 & 0.38 & 0.39 & 0.43 \\
\hline
\end{tabular}

This ratio $\overline{\mathrm{I}} / \overline{\mathrm{A}}=0.43$ for man is different from that found for guinea pig $(\overline{\mathrm{I}} / \overline{\mathrm{A}}=0.8)$.

From these data for guinea pig and man it can be suggested that the molecular size-dependent discrimination at the barrier expressed by the ratio of the CSF/plasma concentration quotients of two different proteins is a constant in a single species but this constant varies from species to species.

\section{Discussion}

The albumin CSF/plasma concentration quotient $\mathrm{A}$ is shown to be a function of various parameters like barrier permeability, CSF flow and CSF drainage (4, 7). The permeability of the blood CSF barrier for a single protein depends, amongst other factors, on its invariant molecular size (4) with strong interindividual variations. This ability of the barrier to discriminate according to molecular size can be characterized by the ratio of two concentration quotients like I/A. In particular, the ratio I/A is also known as the IgG-index (8). This discrimination ratio which refers to a single pair of quotients is of course different for different protein pairs, e.g. $\alpha_{2}$-macroglobulin quotient/albumin quotient $=0.23$ in $\operatorname{man}(1)$.

In this communication we show that the discrimination ratio $\mathrm{I} / \mathrm{A}$ in a single species is a constant which does not depend on age and sex and also remains constant for the whole CSF space. But this discrimination ratio seems to be a species-specific constant. In the guinea pig with $\overline{\mathrm{I}} / \overline{\mathrm{A}}=0.8$ there is less size-dependent discrimination than in man with a discrimination constant $\bar{I} / \bar{A}=0.43$. A ratio $I / A=1$ would mean that there is no size-dependent discrimination at all. This can be observed only in the pathological case of a blood CSF barrier dysfunction $(1,9)$.

The fact that the constant is unique for a single species has consequences for a valuable general description of the barrier function for proteins. In terms of a more generalized description of body fluid barriers (4) our data show that the blood CSF barrier in guinea pig has a smaller selectivity than the blood CSF barrier in man. But in the same context (4) our data contradict the suggestion that the restrictional forces to a protein at the barrier, expressed as the total protein blood/body fluid concentration quotient (4), correlate generally with the selectivity of the barrier (4). This suggestion is in contrast to the data for man where different protein ratios ( $\overline{\mathrm{A}}$ in tab. 1$)$ correspond to a constant selectivity; this is even more apparent if the cisternal CSF of guinea pigs is compared with ventricular CSF of man with similar protein quotients ( $\overline{\mathrm{A}}$ in tab. 1$)$, but with a selectivity significantly different in both species.

An additional argument against a positive correlation between restrictional forces at the barrier and selectivity is given by the protein quotient ratios in aqueous humour, a compartment with flow and drainage characteristics different from the CSF space: in spite of an extraordinarily marked sex and age dependent aqueous humour/plasma protein concentration quotients, a constant selectivity for these groups was observed.

This constancy of the I/A ratio in a single species is the basis of our evaluation graph for the CSF protein profile $(1,9)$, which allows the identification of a local IgG synthesis in the central nervous system independent of the actual variations of barrier permeability or the location or volume of the CSF sample (1). The species-dependent difference in the discrimination constant has to be taken into account for comparison of CSF data from guinea pig with experimental allergic encephalomyelitis as a model (2) with CSF data from man with multiple sclerosis. For such a comparison (9) we developed for the guinea pig a complete evaluation graph in analogy to that introduced in clinical chemistry for discrimination of blood CSF barrier dysfunctions and inflammatory reactions in the central nervous system of man (1). 


\section{Acknowledgement}

A part of this work belongs to the thesis of $P$. Thiele and was supported by the SFB 33.

\section{References}

1. Reiber, H. (1980) J. Neurol. 224, 89-99.

2. Wisniewski, H. M., Lassmann, H., Brosnan, C. F., Mehta, P. D.. Lidsky, A. A. \& Madrid, R. R. (1982) in Recent Adv. Clin. Neurol. (Matthews, W. B. \& Glaser, G. H., eds.) 3, 95-124, Churchill, Livingstone.

3. Reiber, H. \& Schunck, O. (1983) Lab. Animals 17, 25-27.

4. Felgenhauer. K. (1980) Pflügers Arch. 384, 9-17.

5. Weisner, B. \& Bernhardt, W. (1978) J. Neurol. Sci. 37, 205214.
6. Reiber, H. (1979) J. Clin. Chem. Clin. Biochem. 17, 587591.

7. Bradbury, M. (1979) The concept of a blood-brain barrier, pp. 17-37, J. Wiley \& soñs, N. Y.

8. Link, H. \& Tibbling, G. (1977) J. Clin. Lab. Invest. 37, 397401.

9. Suckling, A. J., Reiber, H., Kirby, J. A. \& Rumsby, M. G. (1983) J. Neuroimmunol., in press.

Dr. H. Reiber

Neurochemisches Labor der Neurologischen Klinik

Robert-Koch-Str. 40

D-3400 Göttingen 